\title{
Coincidence and common fixed point results via simulation functions in G-metric spaces
}

\author{
Manoj Kumar ${ }^{a, *}$, Sahil Arora ${ }^{b}$, Mohammad Imdad ${ }^{\mathrm{c}}$, Waleed M. Alfaqih ${ }^{\mathrm{b}}$ \\ a Department of Mathematics, Starex University, Gurugram, India. \\ ${ }^{b}$ Department of Mathematics, Lovely Professional University, Punjab, India. \\ ${ }^{c}$ Department of Mathematics, Aligarh Muslim University, Aligarh, India.
}

\begin{abstract}
In this work, we establish some coincidence and common fixed point theorems in symmetrical G-metric space via simulation functions. In the presented work, we extend the results of Argoubi et al. [H. Argoubi, B. Samet, C. Vetro, J. Nonlinear Sci. Appl., 8 (2015), 1082-1094] by using the concept of G-metric space. An illustrative example is also given to show the genuineness of our results. We also apply our results to derive some coincidence and common fixed point results for right monotone simulation function in the framework of G-metric space.
\end{abstract}

Keywords: Simulation function, right monotone simulation function, G-metric space, coincident point, fixed point. 2010 MSC: 47H10, 54H25.

(C)2019 All rights reserved.

\section{Introduction}

One of the earliest and most important results in fixed point theory is Banach contraction principle [7] which states that every contraction mapping defined on a complete metric space possesses a unique fixed point. Due to its applications in many disciplines within mathematics and outside it, several authors have improved, generalized and extended this principle in nonlinear analysis (e.g. [1-3, 8-10, 12, 15, 22]). In this regard, Khojasteh et al. [14], in 2015, introduced the notion of simulation functions and utilized the same to generalize Banach contraction principle. Thereafter, Roldán-López-de Hierro et al. [21] and Argoubi [6] modified the notion of simulation functions and proved some coincidence and common fixed point theorems utilizing the newly larger class of simulation functions. Mustafa and Sims (see [17, 18]) introduced a new notion of generalized metric spaces known as G-metric spaces as follows:

Definition 1.1. Let $X$ be a non-empty set and $G: X^{3} \rightarrow[0, \infty)$ a mapping which satisfies the following properties: (for all $x, y, z, a \in X:$ )

\footnotetext{
*Corresponding author

Email address: manojantil18@gmail.com (Manoj Kumar)

doi: $10.22436 /$ jmcs.019.04.08
}

Received: 2019-05-11 Revised: 2019-06-05 Accepted: 2019-07-01 
(i) $G(x, y, z)=0$, if $x=y=z$;

(ii) $0<G(x, x, y)$ whenever $x \neq y$, for all $x, y \in X$;

(iii) $G(x, x, y) \leqslant G(x, y, z), y \neq z$;

(iv) $\mathrm{G}(x, y, z)=\mathrm{G}(x, z, y)=\mathrm{G}(y, x, z)=\mathrm{G}(z, x, y)=\mathrm{G}(y, z, x)=\mathrm{G}(z, y, x)$;

(v) $G(x, y, z) \leqslant G(x, a, a)+G(a, y, z)$.

Then the function $G$ is said to be $G$-metric on $X$ and the pair $(X, G)$ is known as $G$ metric space.

The following definitions and auxiliary results in G-metric spaces given by Mustafa and Sims (see $[17,18])$ will be used in the sequel.

Definition 1.2. Let $(X, G)$ be a $G$-metric space and $\left\{x_{n}\right\}$ be a sequence of points in $X$.

- If there exists $x \in X$ such that $\left\{x_{n}\right\}$ if $\lim _{n, m \rightarrow \infty} G\left(x, x_{n}, x_{m}\right)=0$, then $x$ is said to be the limit point of $\left\{x_{n}\right\}$ and we say that the sequence $\left\{x_{n}\right\}$ is G-convergent to $x$.

- The sequence $\left\{x_{n}\right\}$ is said to be G-Cauchy, if given any $\epsilon>0$ there is $N \in \mathbb{N}$ such that

$$
\mathrm{G}\left(\mathrm{x}_{\mathrm{n}}, \mathrm{x}_{\mathrm{m}}, \mathrm{x}_{\mathrm{l}}\right)<\epsilon, \forall \mathrm{n}, \mathrm{m}, \mathrm{l} \geqslant \mathrm{N} .
$$

- If every $\mathrm{G}$-Cauchy sequence in $(X, G)$ is $G$-convergent in $X$, then $(X, G)$ is called $G$-complete.

Definition 1.3. Let $(X, G)$ be a $G$-metric space. If $G(x, y, y)=G(x, x, y)$ for all $x, y \in X$, then $(X, G)$ is called symmetric.

Example 1.4. The following are some examples of G-metric spaces.

- Let $(X, d)$ be a metric space. Define $G: X^{3} \rightarrow[0, \infty)$ by

$$
\mathrm{G}(x, y, z)=\mathrm{d}(x, y)+\mathrm{d}(y, z)+\mathrm{d}(x, z), \quad \forall x, y, z \in X .
$$

Then it is clear that $(X, G)$ is a symmetric $G$-metric space.

- Let $X=\{a, b\}$. Define $G$ by

$$
\begin{aligned}
& G(a, a, a)=G(b, b, b)=0 ; \\
& G(a, a, b)=1 ; \\
& G(a, b, b)=2 .
\end{aligned}
$$

Now, extend $G$ to $X^{3}$ by using the symmetry in the variables. Then it is clear that $(X, G)$ is a symmetric G-metric space.

In this paper, we establish some coincidence and common fixed point theorems in symmetrical Gmetric space via simulation functions. In the presented work, we extend the results of Argoubi [6] by using the concept of G-metric space. We also apply our main theorem to derive coincidence and common fixed point results for metric space.

\section{Simulation functions}

Khojasteh et al. [14] introduced the class of simulation functions as under.

Definition 2.1. A simulation function $\zeta$ is a function $\zeta:[0, \infty) \times[0, \infty) \rightarrow \mathbb{R}$ satisfying the following:

$\left(\zeta_{1}\right) \zeta(0,0)=0$; 
$\left(\zeta_{2}\right) \zeta(a, b)<b-a, \forall a, b>0 ;$

$\left(\zeta_{3}\right)$ if $\left\{a_{n}\right\},\left\{b_{n}\right\} \subseteq(0, \infty)$ satisfying $\lim _{n \rightarrow \infty}\left\{a_{n}\right\}=\lim _{n \rightarrow \infty}\left\{b_{n}\right\}=\ell$, then

$$
\lim _{n \rightarrow \infty} \sup \zeta\left(a_{n}, b_{n}\right)<0 \text {. }
$$

The authors in [14] utilized the above class of auxiliary functions to define Z-contractions as follows.

Definition 2.2. Let $(X ; d)$ be a metric space, $T: X \rightarrow X$ and $\zeta \in Z$. Then $T$ is called a Z-contraction with respect to $\zeta$ if the following condition is satisfied

$$
\zeta(d(T x ; T y) ; d(x ; y)) \geqslant 0, \quad \forall x, y \in X .
$$

Khojasteh et al. [14] proved the following result.

Theorem 2.3. Every Z-contraction mapping defined on a complete metric space admits a unique fixed point.

In 2015, Roldan et al. [21] gave some observations on the class of Z-functions. His observations leaded him to enlarge the class of $z$-functions by modify the condition $\zeta_{3}$ as follows:

$\left(\zeta_{3}^{\prime}\right)$ if $\left\{a_{n}\right\},\left\{b_{n}\right\} \subseteq(0, \infty)$ such that $\lim _{n \rightarrow \infty}\left\{a_{n}\right\}=\lim _{n \rightarrow \infty}\left\{b_{n}\right\}=\ell$, and $a_{n}<b_{n}$ for all $n \in \mathbb{N}$, then

$$
\lim _{n \rightarrow \infty} \sup \zeta\left(a_{n}, b_{n}\right)<0 \text {. }
$$

Next, we present some examples of simulation functions.

Example 2.4 (see $[5,11,14,21]$ ). We define the mappings $\zeta_{i}:[0, \infty) \times[0, \infty) \rightarrow \mathbb{R}$ for $i=1,2,3,4,5$, as follows:

1. $\zeta_{1}(a, b)=\lambda b-a, \forall a, b \in[0, \infty)$, where $\lambda \in[0,1)$.

2. $\zeta_{2}(a, b)=\frac{b}{b+1}-a, \forall a, b \in[0, \infty)$.

3. $\zeta_{3}(a, b)=\psi(b)-\phi(a), \forall a, b \in[0, \infty)$, where $\phi, \psi:[0, \infty) \rightarrow[0, \infty)$ are two continuous functions such that $\psi(a)=\phi(a)=0$ if and only if $a=0$ and $\psi(a)<a \leqslant \phi(a), \forall a>0$.

4. $\zeta_{4}(a, b)=b-\eta(b)-a, \forall a, b \in[0, \infty)$, where $\eta:[0, \infty) \rightarrow[0, \infty)$ is a lower semi continuous function such that $\eta(a)=0$ if and only if $a=0$.

5. $\zeta_{5}(a, b)=b-\int_{0}^{a} \varphi(u) d u, \forall a, b \in[0, \infty)$, where $\varphi:[0, \infty) \rightarrow[0, \infty)$ is a function such that $\int_{0}^{\epsilon} \varphi(a) d a$ exists and $\int_{0}^{\epsilon} \varphi(a) d a>\epsilon$, for each $\epsilon>0$.

\section{Main results}

In this section, we prove our main results as follows.

Theorem 3.1. Let $(\mathrm{X}, \mathrm{G})$ be a symmetric complete $\mathrm{G}$-metric space and $\mathrm{S}, \mathrm{T}: \mathrm{X} \rightarrow \mathrm{X}$. Suppose that

(i) $S(X) \subseteq T(X)$;

(ii) $\mathrm{T}(\mathrm{X})$ is closed;

(iii) $\mathrm{S}$ is T-non-decreasing;

(iv) $\exists \mathrm{x}_{0} \in \mathrm{X}$ with $\mathrm{T} \mathrm{x}_{0} \leqslant S \mathrm{x}_{0}$;

(v) if $\left\{\mathrm{T} \mathrm{x}_{\mathrm{n}}\right\} \subset \mathrm{X}$ is a nondecreasing sequence (w.r.t. $\leqslant$ ) with $\mathrm{T} \mathrm{x}_{\mathrm{n}} \rightarrow \mathrm{Tz}$ in $\mathrm{T}(\mathrm{X})$, then $\mathrm{Tu} \leqslant \mathrm{T}(\mathrm{Tu})$ and $T x_{n} \leqslant T u$, for all $n \in N$; 
(vi) there exists a simulation function $\zeta$ such that for every $(x, y) \in X \times X$ with $T x \leqslant T y$, we have

$$
\zeta(G(S x, S y, S z), H(S, T, x, y, z)) \geqslant 0,
$$

where

$$
H(S, T, x, y, z)=\max \{G(T x, T y, T z), G(T x, S y, T z), G(T y, S x, T z), G(T x, S x, T z), G(T y, S y, T z)\} .
$$

Then $\mathrm{S}$ and $\mathrm{T}$ have a coincidence point. Further, if $\mathrm{S}$ and $\mathrm{T}$ commute at their coincidence points, then $\mathrm{S}$ and $\mathrm{T}$ have a common fixed point.

Before proving Theorem 3.1, we prove the following lemmas which are needed in the sequel.

Lemma 3.2. Let $(X, G)$ be a symmetric $\mathrm{G}$-metric space and $\mathrm{S}, \mathrm{T}$ satisfies the conditions of Theorem 3.1. Let $\left\{x_{\mathrm{n}}\right\}$ be a sequence in $\mathrm{X}$ such that $\mathrm{T} \mathrm{x}_{\mathrm{n}+1}=\mathrm{S} \mathrm{x}_{\mathrm{n}}$ for all $n \in \mathrm{N}$. If $\mathrm{T} \mathrm{x}_{\mathrm{n}} \neq \mathrm{T} \mathrm{x}_{\mathrm{n}+1}$ for all $n \in \mathrm{N}$, then

$$
\lim _{n \rightarrow \infty} G\left(T x_{n}, T x_{n}, T x_{n+1}\right)=0 .
$$

Proof. Using (iii) and (iv) of Theorem 3.1, we have

$$
T x_{0} \leqslant T x_{1} \leqslant T x_{2} \leqslant \cdots \leqslant T x_{n} \leqslant T x_{n+1}
$$

It follows from (vi) of Theorem 3.1 that

$$
0 \leqslant \zeta\left(G\left(S x_{n-1}, S x_{n-1}, S x_{n}\right), H\left(S, T, x_{n-1}, x_{n-1}, x_{n}\right)\right),
$$

that is,

$$
0 \leqslant \zeta\left(G\left(T x_{n}, T x_{n}, T x_{n+1}\right), H\left(S, T, x_{n-1}, x_{n-1}, x_{n}\right)\right),
$$

where

$$
\begin{aligned}
H\left(S, T, x_{n-1}, x_{n-1}, x_{n}\right)=\max \left\{G\left(T x_{n-1}, T x_{n-1}, T x_{n}\right), G\left(T x_{n-1}, S x_{n-1}, T x_{n}\right),\right. \\
\left.\quad G\left(T x_{n-1}, S x_{n-1}, T x_{n}\right), G\left(T x_{n-1}, S x_{n-1}, T x_{n}\right), G\left(T x_{n-1}, S x_{n-1}, T x_{n}\right)\right\} .
\end{aligned}
$$

Again, using the assumption of Lemma 3.2, we get

$$
\begin{aligned}
H\left(S, T, x_{n-1}, x_{n-1}, x_{n}\right)= & \max \left\{G\left(T x_{n-1}, T x_{n-1}, T x_{n}\right), G\left(T x_{n-1}, T x_{n}, T x_{n}\right),\right. \\
& \left.G\left(T x_{n-1}, T x_{n}, T x_{n}\right), G\left(T x_{n-1}, T x_{n}, T x_{n}\right), G\left(T x_{n-1}, T x_{n}, T x_{n}\right)\right\} \\
= & \max \left\{G\left(T x_{n-1}, T x_{n-1}, T x_{n}\right), G\left(T x_{n-1}, T x_{n}, T x_{n}\right)\right\} .
\end{aligned}
$$

As $(X, G)$ is symmetric $G$-metric space, we have

$$
H\left(S, T, x_{n-1}, x_{n-1}, x_{n}\right)=G\left(T x_{n-1}, T x_{n-1}, T x_{n}\right) .
$$

From the condition $\zeta_{2}$, we have

$$
\begin{aligned}
& 0 \leqslant \zeta\left(G\left(T x_{n}, T x_{n}, T x_{n+1}\right), G\left(T x_{n-1}, T x_{n-1}, T x_{n}\right)\right) \\
&<G\left(T x_{n-1}, T x_{n-1}, T x_{n}\right)-G\left(T x_{n}, T x_{n}, T x_{n+1}\right) \\
& G\left(T x_{n}, T x_{n}, T x_{n+1}\right)<G\left(T x_{n-1}, T x_{n-1}, T x_{n}\right) .
\end{aligned}
$$

The above inequality proves that $\left\{\mathrm{G}\left(T x_{n-1} . T x_{n-1}, T x_{n}\right)\right\}$ is a monotonic decreasing sequence of nonnegative reals and hence it must be convergent. So, there exists $u \geqslant 0$ such that

$$
\lim _{n \rightarrow \infty} G\left(T x_{n}, T x_{n}, T x_{n+1}\right)=u .
$$


Claim $u=0$. Assume that $u>0$. Using the condition $\zeta_{3}$, we obtain

$$
0 \leqslant \sup \zeta\left(G\left(T x_{n}, T x_{n}, T x_{n+1}\right), G\left(T x_{n-1}, T x_{n-1}, T x_{n}\right)\right)<0,
$$

a contradiction. Hence, it must be $u=0$. Therefore,

$$
\lim _{n \rightarrow \infty} G\left(T x_{n}, T x_{n}, T x_{n+1}\right)=0 .
$$

As required.

Lemma 3.3. Let $(\mathrm{X}, \mathrm{G})$ be a symmetric G-metric space and $\mathrm{S}, \mathrm{T}$ satisfy the conditions of Theorem 3.1. Let $\left\{x_{\mathrm{n}}\right\}$ be a sequence in $\mathrm{X}$ such that $\mathrm{T} \mathrm{x}_{\mathrm{n}+1} \neq \mathrm{T} \mathrm{x}_{\mathrm{n}}$ for each $n \in \mathrm{N}$. Then, the sequence $\left\{\mathrm{T} \mathrm{x}_{\mathrm{n}}\right\}$ is bounded.

Proof. Suppose that $\left\{T x_{n}\right\}$ is not bounded. Then there exists $\left\{x_{n_{j}}\right\} \subseteq\left\{x_{n}\right\}$ such that $n_{1}=1$ and for each $k \in N, n_{j+1}$ is the minimum integer satisfying

$$
G\left(T x_{n_{j+1}}, T x_{n_{j}}, T x_{n_{j}}\right)>1,
$$

and

$$
G\left(T x_{k}, T x_{n_{j}}, T x_{n_{j}}\right) \leqslant 1,
$$

for $n_{j} \leqslant k \leqslant n_{j+1}-1$. By using the triangle inequality, we get

$$
\begin{aligned}
1 & <G\left(T x_{n_{j}+1}, T x_{n_{j}}, T x_{n_{j}}\right) \\
& \leqslant G\left(T x_{n_{j}+1}, T x_{n_{j+1}-1}, T x_{n_{j+1}-1}\right)+G\left(T x_{n_{j+1}-1}, T x_{n_{j}}, T x_{n_{j}}\right) \\
& \leqslant G\left(T x_{n_{j}+1}, T x_{n_{j+1}-1}, T x_{n_{j+1}-1}\right)+1 .
\end{aligned}
$$

Letting $j \rightarrow \infty$ and making use of Lemma 3.2, we obtain

$$
G\left(T x_{n_{j}+1}, T x_{n_{j}}, T x_{n_{j}}\right)=1 .
$$

By applying the triangle inequality, we have

$$
\begin{aligned}
1 & <G\left(T x_{n_{j}+1}, T x_{n_{j}}, T x_{n_{j}}\right) \\
& \leqslant G\left(T x_{n_{j}+1}-1, T x_{n_{j}-1}, T x_{n_{j}-1}\right) \\
& \leqslant G\left(T x_{n_{j}+1}-1, T x_{n_{j}}, T x_{n_{j}}\right)+G\left(T x_{n_{j}}, T x_{n_{j}-1}, T x_{n_{j}-1}\right) \\
& \leqslant 1+G\left(T x_{n_{j}}, T x_{n_{j}-1}, T x_{n_{j}-1}\right) .
\end{aligned}
$$

By making use of Lemma 3.2 and letting $j \rightarrow \infty$, we get

$$
\lim _{j \rightarrow \infty} G\left(T x_{n_{j}+1}-1, T x_{n_{j}-1}, T x_{n_{j}-1}\right)=1 .
$$

Again, due to the triangle inequality, we have

$$
\left|G\left(T x_{n_{j}+1}-1, T x_{n_{j}}, T x_{n_{j}}\right)-G\left(T x_{n_{j}}, T x_{n_{j}+1}, T x_{n_{j}+1}\right)\right| \leqslant G\left(T x_{n_{j+1}-1}, T x_{n_{j+1}}, T x_{n_{j+1}}\right) .
$$

By making use of Lemma 3.2 and tending $j \rightarrow \infty$, we obtain

$$
\lim _{j \rightarrow \infty} G\left(T x_{n_{j}+1}-1, T x_{n_{j}}, T x_{n_{j}}\right)=1 .
$$

Using similar argument, we obtain

$$
\left|G\left(T x_{n_{j}-1}, T x_{n_{j+1}}, T x_{n_{j+1}}\right)-G\left(T x_{n_{j}-1}, T x_{n_{j+1}-1}, T x_{n_{j+1}-1}\right)\right| \leqslant G\left(T x_{n_{j+1}}, T x_{n_{j+1}-1}, T x_{n_{j+1}-1}\right) .
$$


Letting $j \rightarrow \infty$ and using Lemma 3.2, we obtain

$$
\lim _{j \rightarrow \infty} G\left(T x_{n_{j}-1}, T x_{n_{j+1}}, T x_{n_{j+1}}\right)=1 .
$$

From (3.2), (3.3), (3.4) and Lemma 3.2, we have

$$
\mathrm{H}\left(\mathrm{S}, \mathrm{T}, \mathrm{x}_{\mathrm{n}_{\mathrm{j}+1}-1}, \mathrm{x}_{\mathrm{n}_{\mathrm{j}}-1}, \mathrm{x}_{\mathrm{n}_{\mathrm{j}}-1}\right)=1 .
$$

Applying the condition $\zeta_{3}$ of Definition 2.1 and (3.1), (3.2), (3.3), (3.4) and (3.5), we get

$$
0 \leqslant \lim _{j \rightarrow \infty} \sup \zeta\left(G\left(T x_{n_{j}+1}, T x_{n_{j}}, T x_{n_{j}}\right), H\left(S, T, x_{n_{j+1}-1}, x_{n_{j}-1}, x_{n_{j}-1}\right)\right)<0,
$$

a contradiction. This ends the proof.

Lemma 3.4. Let (X, G) be a symmetric G-metric space and $\mathrm{S}, \mathrm{T}$ satisfy the conditions of Theorem 2.3. Let $\left\{x_{\mathrm{n}}\right\}$ be a sequence in $\mathrm{X}$ such that $\mathrm{T} \mathrm{x}_{\mathrm{n}+1}=\mathrm{S} \mathrm{x}_{\mathrm{n}}$, for all $n \in \mathrm{N}$. If $\mathrm{T} \mathrm{x}_{\mathrm{n}} \neq \mathrm{T} \mathrm{x}_{\mathrm{n}+1}$ for all $n \in \mathrm{N}$, then $\left\{\mathrm{T} \mathrm{x}_{\mathrm{n}}\right\}$ is a Cauchy sequence.

Proof. Consider

$$
A_{n}=\sup \left\{G\left(T x_{p}, T x_{q}, T x_{q}\right): p, q \geqslant n\right\} .
$$

In view of Lemma 3.3, the sequence $\left\{T x_{n}\right\}$ is bounded. So, $A_{n}<\infty$, for each $n \in N$ which implies that, $\left\{A_{n}\right\}$ is monotonic and bounded sequence and hence is convergent. Therefore, there exists $A \geqslant 0$ such that

$$
\lim _{n \rightarrow \infty} A_{n}=A .
$$

We will prove that $A=0$.

Let us suppose contrary that $A>0$. By the definition of $A_{n}$, for each $j \in N$, there exist $n_{j}, m_{j} \in N$ such that $m_{j}>n_{j} \geqslant j$ and

$$
A_{j}-\frac{1}{j}<G\left(T x_{m_{j}}, T x_{n_{j}}, T x_{n_{j}}\right) \leqslant A_{j} .
$$

Therefore,

$$
\lim _{j \rightarrow \infty} G\left(T x_{m_{j}}, T x_{n_{j}}, T x_{n_{j}}\right)=A .
$$

Using Lemma 3.3 and triangle inequality, we get

$$
\begin{aligned}
G\left(T x_{m_{j}}, T x_{n_{j}}, T x_{n_{j}}\right) & \leqslant G\left(T x_{m_{j-1}}, T x_{n_{j-1}}, T x_{n_{j-1}}\right) \\
& \leqslant G\left(T x_{m_{j-1}}, T x_{m_{j}}, T x_{m_{j}}\right)+G\left(T x_{m_{j}}, T x_{n_{j}}, T x_{n_{j}}\right)+G\left(T x_{n_{j}}, T x_{n_{j-1}}, T x_{n_{j-1}}\right) .
\end{aligned}
$$

Using (3.6), Lemma 3.3 and letting $j \rightarrow \infty$, we obtain

$$
\lim _{j \rightarrow \infty} G\left(T x_{m_{j-1}}, T x_{n_{j-1}}, T x_{n_{j-1}}\right)=A .
$$

Proceeding in the same way, we can prove that

$$
\lim _{j \rightarrow \infty} G\left(T x_{m_{j-1}}, T x_{n_{j}}, T x_{n_{j}}\right)=A,
$$

and

$$
\lim _{j \rightarrow \infty} G\left(T x_{n_{j-1}}, T x_{m_{j}}, T x_{m_{j}}\right)=A .
$$

Using (3.7), (3.8), (3.9) and Lemma 3.3, we get

$$
\lim _{j \rightarrow \infty} H\left(S, T, x_{m_{j}-1}, x_{n_{j}-1}, x_{n_{j}-1}\right)=A .
$$


Using (3.1), (3.6), (3.10) and the condition of simulation function, we obtain

$$
0 \leqslant \lim _{j \rightarrow \infty} \sup \zeta\left(G\left(T x_{m_{j}}, T x_{n_{j}}, T x_{n_{j}}\right), H\left(S, T, x_{m_{j}-1}, x_{n_{j}-1}, x_{n_{j}-1}\right)\right)<0 .
$$

This contradiction shows that $A=0$. So,

$$
\lim _{j \rightarrow \infty} A_{j}=0
$$

Hence, $\left\{T x_{n}\right\}$ is a Cauchy sequence.

Proof. Due to Lemma 3.4, $\left\{T x_{n}\right\}$ is Cauchy. The completeness of $X$ ensures the existence of some $u \in X$ satisfying

$$
\mathrm{T} x_{\mathrm{n}} \rightarrow \mathrm{Tu} \text {, when } \mathrm{n} \rightarrow \infty \text {. }
$$

Let us assume that $\mathrm{G}(\mathrm{Su}, \mathrm{Tu}, \mathrm{Tu})>0$. Using (3.11) and letting $n \rightarrow \infty$, we obtain

$$
\begin{aligned}
\mathrm{H}\left(\mathrm{S}, \mathrm{T}, \mathrm{x}_{\mathrm{n}}, \mathrm{u}, \mathrm{u}\right) & =\max \left\{\mathrm{G}\left(T x_{n}, T u, T u\right), \mathrm{G}\left(T x_{n}, S u, T u\right), G\left(T u, S x_{n}, T u\right), G\left(T x_{n}, S x_{n}, T u\right), G(T u, S u, T u)\right\} \\
& =\max \{G(T u, T u, T u), G(T u, S u, T u), G(T u, S u, T u), G(T u, S u, T u), G(T u, S u, T u)\} \\
& =G(S u, T u, T u)>0 .
\end{aligned}
$$

Using (3.1), (3.11) and $\left(\zeta_{3}\right)$, we get

$$
0 \leqslant \lim _{j \rightarrow \infty} \sup \zeta\left(G\left(S u, T x_{n+1}, T x_{n+1}\right), H\left(S, T, x_{n}, u, u\right)\right)<0 .
$$

This contradiction shows that $\mathrm{G}(\mathrm{Su}, \mathrm{Tu}, \mathrm{Tu})=0$. So, $u$ is a coincident point of $\mathrm{S}$ and $\mathrm{T}$.

Let $v=T u=S v$. Since, $S$ and $T$ commute at their coincident point $u$. Therefore,

$$
\mathrm{S} v=\mathrm{S}(\mathrm{Tu})=\mathrm{T}(\mathrm{Su})=\mathrm{T} v \text {. }
$$

By $(v)$, we have $T u \leqslant T(T u)=T$.

$$
\begin{aligned}
\mathrm{H}(\mathrm{S}, \mathrm{T}, \mathrm{v}, \mathrm{u}, \mathrm{u}) & =\max \{\mathrm{G}(\mathrm{T} v, \mathrm{Tu}, \mathrm{Tu}), \mathrm{G}(\mathrm{T} v, \mathrm{Su}, \mathrm{Tu}), \mathrm{G}(\mathrm{Tu}, \mathrm{S} v, \mathrm{Tu}), \mathrm{G}(\mathrm{T} v, \mathrm{~S} v, \mathrm{Tu}), \mathrm{G}(\mathrm{Tu}, \mathrm{Su}, \mathrm{Tu})\} \\
& =\max \{\mathrm{G}(\mathrm{T} v, v, v), \mathrm{G}(\mathrm{T} v, v, v), \mathrm{G}(v, \mathrm{~S} v, v), \mathrm{G}(\mathrm{T} v, \mathrm{~S} v, v), \mathrm{G}(v, v, v)\} \\
& =\max \{\mathrm{G}(\mathrm{T} v, v, v), \mathrm{G}(\mathrm{T} v, T v, v)\} .
\end{aligned}
$$

Since, $(X, G)$ is symmetric $G$-metric space. Therefore, $H(S, T, v, u, u)=G(T v, v, v)$. Using (3.1) and $\left(\zeta_{3}\right)$, we get

$$
0 \leqslant \lim _{j \rightarrow \infty} \sup \zeta(G(S v, S u, S u), H(S, T, v, u, u))=\lim _{j \rightarrow \infty} \sup \zeta(G(S v, v, v), G(S v, v, v))<0,
$$

which is a contradiction. So, $\mathrm{G}(v, v, \mathrm{~T} v)=0$, which implies that $v=\mathrm{T} v=\mathrm{S} v$. Therefore, $v$ is common fixed point of $S$ and $T$.

Next, we provide an illustrative example which exhibits the utility of Theorem 3.1.

Example 3.5. Let $X=[0,1]$ associated with the $G$-metric defined by $G(x, y, z)=\max \{|z-x|,|x-y|,|y-z|\}$ for every $x, y, z \in X$. Without any loss of generality, let us assume that $z \leqslant y \leqslant x$. Therefore $G(x, y, z)=$ $|x-z|$. Define the mappings $S, T: X \rightarrow X$ by $S x=\frac{x}{25}$ and $T x=\frac{\chi}{5}$ for each $x \in X$. Evidently, conditions (i) to (v) of Theorem 3.1 are fulfilled for $x_{0}=0$. Let $\zeta: X \times X \rightarrow \mathbb{R}$ be given by

$$
\zeta(a, b)=\theta b-a,
$$

for $\theta \in[0,1)$. Indeed for all $x \neq y \neq z$, we have

$$
\zeta(\mathrm{G}(\mathrm{S} x, \mathrm{Sy}, \mathrm{Sz}), \mathrm{H}(\mathrm{S}, \mathrm{T}, x, y, z))=\theta \mathrm{H}(\mathrm{S}, \mathrm{T}, \mathrm{x}, \mathrm{y}, z)-\mathrm{G}(\mathrm{Sx}, \mathrm{Sy}, \mathrm{Sz}) .
$$


If we specially choose $\theta=\frac{1}{3}$, we have

$$
\zeta(G(S x, S y, S z), H(S, T, x, y, z))=\frac{1}{3} H(S, T, x, y, z)-G(S x, S y, S z) .
$$

In fact for every $x, y, z \in X$, we have

$$
\begin{aligned}
\mathrm{G}(\mathrm{S} x, \mathrm{Sy}, \mathrm{Sz}) & =\left|\frac{x}{25}-\frac{z}{25}\right| \\
& \leqslant \frac{1}{4}\left|\frac{x}{5}-\frac{z}{5}\right| \\
& =\frac{1}{4} \mathrm{G}(\mathrm{T} x, \mathrm{~T} y, \mathrm{~T} z) \\
& \leqslant \frac{1}{3} \mathrm{H}(\mathrm{S}, \mathrm{T}, \mathrm{x}, \mathrm{y}, z),
\end{aligned}
$$

which implies that

$$
\frac{1}{3} H(S, T, x, y, z)-G(S x, S y, S z) \geqslant 0 .
$$

On account of (3.12) and (3.13), we obtain

$$
\zeta(G(S x, S y, S z), H(S, T, x, y, z)) \geqslant 0 .
$$

Therefore, all the assumptions of Theorem 3.1 are fulfilled. Consequently, $\mathrm{S}$ and T have a coincident point (namely: $0 \in X$ ). Also, $S$ and $T$ commute at 0 , which yields that 0 is a unique common fixed point $S$ and T.

From Theorem 3.1, we can deduce several results of coincidence and common fixed point by means of simulation mapping.

Corollary 3.6. Let $(\mathrm{X}, \mathrm{G})$ be a symmetric $\mathrm{G}$-metric space and $\mathrm{S}, \mathrm{T}: \mathrm{X} \rightarrow \mathrm{X}$. Suppose that

(i) $S(X) \subseteq T(X)$;

(ii) $\mathrm{T}(\mathrm{X})$ is closed;

(iii) $\mathrm{S}$ is T-non-decreasing;

(iv) $\exists \mathrm{x}_{0} \in \mathrm{X}$ with $\mathrm{gx_{0 }} \leqslant \mathrm{fx_{0 }}$;

(v) if $\mathrm{T} \mathrm{x}_{\mathrm{n}} \subset \mathrm{X}$ is a nondecreasing sequence (w.r.t. $\leqslant$ ) with $\mathrm{T} \mathrm{x}_{\mathrm{n}} \rightarrow \mathrm{T} z$ in $\mathrm{T}(\mathrm{X})$, then $\mathrm{Tu} \leqslant \mathrm{T}(\mathrm{Tu})$ and $\mathrm{T} \mathrm{x}_{\mathrm{n}} \leqslant \mathrm{Tu}$, for all $\mathrm{n} \in \mathrm{N}$;

(vi) there exists a monotone simulation function $\zeta$ such that for every $(x, y) \in X \times X$ with $T x \leqslant T y$, we have

$$
\zeta(G(S x, S y, S z), G(T x, T y, T z)) \geqslant 0 .
$$

Then $\mathrm{S}$ and $\mathrm{T}$ have a coincidence point. Further, if $\mathrm{S}$ and $\mathrm{T}$ commute at their coincidence points, then $\mathrm{S}$ and $\mathrm{T}$ have a common fixed point.

Proof. We know that

$$
G(T x, T y, T z) \leqslant H(S, T, x, y, z),
$$

for each $x, y, z \in X$. 
Let $\zeta: X \times X \rightarrow \mathbb{R}$ be defined as

$$
\zeta(a, b)=\theta b-a,
$$

for $\theta \in[0,1)$. Owing to the given assumption, we have

$$
\begin{aligned}
0 & \leqslant \zeta(G(S x, S y, S z), G(T x, T y, T z)) \\
& <G(T x, T y, T z)-G(S x, S y, S z) .
\end{aligned}
$$

On account of (3.14), we obtain

$$
\begin{aligned}
G(S x, S y, S z) & <G(T x, T y, T z) \\
& \leqslant H(S, T, x, y, z),
\end{aligned}
$$

which yields that

$$
\zeta(\mathrm{G}(\mathrm{S} x, \mathrm{Sy}, \mathrm{Sz}), \mathrm{H}(\mathrm{S}, \mathrm{T}, \mathrm{x}, \mathrm{y}, z)) \geqslant 0 .
$$

It follows from Theorem 3.1 that $S$ and $T$ have a coincidence point and common fixed point.

Corollary 3.7. Let $(\mathrm{X}, \mathrm{G})$ be a symmetric $\mathrm{G}$-metric space and $\mathrm{S}, \mathrm{T}: \mathrm{X} \rightarrow \mathrm{X}$. Suppose that

(i) $\mathrm{S}(\mathrm{X}) \subseteq \mathrm{T}(\mathrm{X})$;

(ii) $\mathrm{T}(\mathrm{X})$ is closed;

(iii) $\mathrm{S}$ is T-non-decreasing;

(iv) $\exists \mathrm{x}_{0} \in X$ with $\mathrm{gx} 0 \leqslant \mathrm{fx}_{0}$;

(v) if $\mathrm{T} \mathrm{x}_{\mathrm{n}} \subset \mathrm{X}$ is a nondecreasing sequence (w.r.t. $\leqslant$ ) with $\mathrm{T} \mathrm{x}_{\mathrm{n}} \rightarrow \mathrm{T} z$ in $\mathrm{T}(\mathrm{X})$, then $\mathrm{Tu} \leqslant \mathrm{T}(\mathrm{Tu})$ and $\mathrm{T} \mathrm{x}_{\mathrm{n}} \leqslant \mathrm{Tu}$, for all $\mathrm{n} \in \mathrm{N}$;

(vi) there exists a simulation function $\zeta$ such that for every $(x, y) \in X \times X$ with $T x \leqslant T y$, we have

$$
\zeta(G(S x, S y, S z), H(S, T, x, y, z)) \geqslant 0,
$$

where

$$
H(S, T, x, y, z)=\max \{G(T x, S x, T z), G(T y, S y, T z)\} .
$$

Then, $\mathrm{S}$ and $\mathrm{T}$ have a coincidence point. Further, if $\mathrm{S}$ and $\mathrm{T}$ commute at their coincidence points, then $\mathrm{S}$ and $\mathrm{T}$ have a common fixed point.

Proof. It can be proved independently by taking any simulation function.

Corollary 3.8. Let $(\mathrm{X}, \mathrm{G})$ be a symmetric $\mathrm{G}$-metric space and $\mathrm{S}, \mathrm{T}: \mathrm{X} \rightarrow \mathrm{X}$. Suppose that

(i) $\mathrm{S}(\mathrm{X}) \subseteq \mathrm{T}(\mathrm{X})$;

(ii) $\mathrm{T}(\mathrm{X})$ is closed;

(iii) $\mathrm{S}$ is T-non-decreasing;

(iv) $\exists \mathrm{x}_{0} \in \mathrm{X}$ with $\mathrm{gx} \mathrm{x}_{0} \leqslant \mathrm{fx}_{0}$;

(v) if $\mathrm{T} x_{n} \subset X$ is a nondecreasing sequence (w.r.t. $\leqslant$ ) with $\mathrm{T} x_{n} \rightarrow T z$ in $\mathrm{T}(\mathrm{X})$, then $\mathrm{Tu} \leqslant \mathrm{T}(\mathrm{Tu})$ and $\mathrm{T} \mathrm{x}_{\mathrm{n}} \leqslant \mathrm{Tu}$, for all $\mathrm{n} \in \mathrm{N}$;

(vi) there exists a simulation function $\zeta$ such that for every $(x, y) \in X \times X$ with $T x \leqslant T y$, we have

$$
\zeta(G(S x, S y, S z), H(S, T, x, y, z)) \geqslant 0,
$$

where

$$
H(S, T, x, y, z)=\max \{G(T x, T y, T z), G(T x, S y, T z), G(T y, S x, T z)\}
$$


Then, $\mathrm{S}$ and $\mathrm{T}$ have a coincidence point. Further, if $\mathrm{S}$ and $\mathrm{T}$ commute at their coincidence points, then $\mathrm{S}$ and $\mathrm{T}$ have a common fixed point.

Proof. It can be proved independently by taking any simulation function.

Corollary 3.9. Let $(\mathrm{X}, \mathrm{G})$ be a symmetric complete $\mathrm{G}$-metric space and $\mathrm{S}: \mathrm{X} \rightarrow \mathrm{X}$. Suppose that

(i) there exists $\mathrm{x}_{0} \in \mathrm{X}$ such that $\mathrm{x}_{0} \leqslant \mathrm{~S} \mathrm{x}_{0}$;

(ii) $(x, y) \in X \times X, x \leqslant y$ implies that $S x \leqslant S y$;

(iii) if $\left\{x_{n}\right\} \subset X$ is a nondecreasing sequence (w.r.t. $\leqslant$ ) with $x_{n} \rightarrow u$ in $X$, then $x_{n} \leqslant u$, for all $n \in N$;

(vi) there exists a simulation function $\zeta$ such that for every $(x, y) \in X \times X$ with $x \leqslant y$, we have

$$
\zeta(G(S x, S y, S z), H(S, x, y, z)) \geqslant 0,
$$

where

$$
H(S, x, y, z)=\max \{G(x, y, z), G(x, S y, z), G(y, S x, z), G(x, S x, z), G(y, S y, z)\} .
$$

Then, $\left\{\mathrm{S}^{\mathrm{n}} \mathrm{x}_{0}\right\}$ converges to fixed point of $\mathrm{S}$.

Proof. Proof follows from Theorem 3.1 by taking $T$ as the identity map.

\section{Coincidence and common fixed point results by means of right monotone simulation mapping}

Definition $4.1([6])$. A function $\zeta:[0, \infty) \times[0, \infty) \rightarrow \mathbb{R}$ is said to be right monotone simulation function, if it satisfies the following

$\left(\zeta_{1}\right) \zeta(0,0)=0$

$\left(\zeta_{2}\right) \zeta(a, b)<b-a, \forall a, b>0$;

$\left(\zeta_{3}\right)$ if $\left\{a_{n}\right\},\left\{b_{n}\right\}$ are sequences in $(0, \infty)$ such that $\lim _{n \rightarrow \infty}\left\{a_{n}\right\}=\lim _{n \rightarrow \infty}\left\{b_{n}\right\}=\ell$, then

$$
\lim _{n \rightarrow \infty} \sup \zeta\left(a_{n}, b_{n}\right)<0 ;
$$

$\left(\zeta_{4}\right)$ if $b_{1} \leqslant b_{2}$, then $\zeta\left(a, b_{1}\right) \leqslant \zeta\left(a, b_{2}\right)$, for all $a, b_{1}, b_{2} \geqslant 0$.

Remark 4.2. Every right monotone simulation function is a simulation function, but the converse is not true.

Example 4.3. Let $\zeta:[0, \infty) \times[0, \infty) \rightarrow \mathbb{R}$ be defined as

$$
\zeta(a, b)=|\sin a|-b,
$$

for each $a, b \geqslant 0$. If we take $b_{1} \leqslant b_{2}$, then $\zeta\left(a, b_{1}\right)$ need not be less than or equal to $\zeta\left(a, b_{2}\right)$ due to monotonic behavior of sin function. Thus, $\zeta$ is a simulation function but not a right monotone simulation function.

From Theorem 3.1, we can prove several results of coincidence and common fixed point by means of right monotone simulation mapping.

Theorem 4.4. Let $(\mathrm{X}, \mathrm{G})$ be a symmetric G-metric space and $\mathrm{S}, \mathrm{T}: \mathrm{X} \rightarrow \mathrm{X}$. Suppose that

(i) $S(X) \subseteq T(X)$; 
(ii) $\mathrm{T}(\mathrm{X})$ is closed;

(iii) $\mathrm{S}$ is T-non-decreasing;

(iv) there exists $\mathrm{x}_{0} \in \mathrm{X}$ with $\mathrm{gx}_{0} \leqslant \mathrm{fx}_{0}$;

(v) if $\mathrm{T} \mathrm{x}_{\mathrm{n}} \subset \mathrm{X}$ is a nondecreasing sequence (w.r.t. $\leqslant$ ) with $\mathrm{T} \mathrm{x}_{\mathrm{n}} \rightarrow \mathrm{T} z$ in $\mathrm{T}(\mathrm{X})$, then $\mathrm{Tu} \leqslant \mathrm{T}(\mathrm{Tu})$ and $\mathrm{T} \mathrm{x}_{\mathrm{n}} \leqslant \mathrm{Tu}$, for all $\mathrm{n} \in \mathrm{N}$;

(vi) there exists a right monotone simulation function $\zeta$ such that for every $(x, y) \in X \times X$ with $T x \leqslant T y$, we have

$$
\zeta(\mathrm{G}(\mathrm{S} x, \mathrm{Sy}, \mathrm{Sz}), \mathrm{G}(\mathrm{Tx}, \mathrm{Ty}, \mathrm{Tz})) \geqslant 0 \text {. }
$$

Then $\mathrm{S}$ and $\mathrm{T}$ have a coincidence point. Further, if $\mathrm{S}$ and $\mathrm{T}$ commute at their coincidence points, then $\mathrm{S}$ and $\mathrm{T}$ have a common fixed point.

Proof. Taking $a=G(S x, S y, S z), b_{1}=G(T x, T y, T z)$ and $b_{2}=H(S, T, x, y, z)$. Owing to the given assumptions, we have

$$
\zeta(G(S x, S y, S z), G(T x, T y, T z)) \geqslant 0 .
$$

We know that

$$
G(T x, T y, T z) \leqslant H(S, T, x, y, z) .
$$

On account of (4.2) and $\zeta_{4}$ property of right simulation function of Definition 4.1, we obtain

$$
\zeta(G(S x, S y, S z), G(T x, T y, T z)) \leqslant \zeta(G(S x, S y, S z), H(S, T, x, y, z)) .
$$

On account of (4.1) and (4.3), we acquire

$$
\zeta(\mathrm{G}(\mathrm{Sx}, \mathrm{Sy}, \mathrm{Sz}), \mathrm{H}(\mathrm{S}, \mathrm{T}, \mathrm{x}, \mathrm{y}, z)) \geqslant 0 .
$$

Now, continuing the same procedure of Theorem 3.1, we get coincidence point and common fixed point of $S$ and $T$.

Corollary 4.5. Let $(\mathrm{X}, \mathrm{G})$ be a symmetric $\mathrm{G}$-metric space and $\mathrm{S}, \mathrm{T}: \mathrm{X} \rightarrow \mathrm{X}$. Suppose that

(i) $S(X) \subseteq T(X)$;

(ii) $\mathrm{T}(\mathrm{X})$ is closed;

(iii) $\mathrm{S}$ is T-non-decreasing;

(iv) there exists $x_{0} \in \mathrm{X}$ with $\mathrm{gx}_{0} \leqslant \mathrm{fx}_{0}$;

(v) if $\mathrm{T} \mathrm{x}_{\mathrm{n}} \subset \mathrm{X}$ is a nondecreasing sequence (w.r.t. $\leqslant$ ) with $\mathrm{T} \mathrm{x}_{\mathrm{n}} \rightarrow \mathrm{Tz}$ in $\mathrm{T}(\mathrm{X})$, then $\mathrm{Tu} \leqslant \mathrm{T}(\mathrm{Tu})$ and $\mathrm{T} \mathrm{x}_{\mathrm{n}} \leqslant \mathrm{Tu}$, for all $\mathrm{n} \in \mathrm{N}$;

(vi) there exists a right monotone simulation function $\zeta$ such that for every $(x, y) \in X \times X$ with $T x \leqslant T y$, we have

$$
\zeta(G(S x, S y, S z), H(S, T, x, y, z)) \geqslant 0
$$

where

$$
H(S, T, x, y, z)=\max \{G(T x, S x, T z), G(T y, S y, T z)\}
$$

Then, $\mathrm{S}$ and $\mathrm{T}$ have a coincidence point. Further, if $\mathrm{S}$ and $\mathrm{T}$ commute at their coincidence points, then $\mathrm{S}$ and $\mathrm{T}$ have a common fixed point. 
Proof. It can be proved independently by taking right monotone simulation function

$$
\zeta:[0, \infty) \times[0, \infty) \rightarrow \mathbb{R},
$$

as $\zeta(a, b)=b-\frac{a+2}{a+1} a$, for each $a, b \geqslant 0$.

Corollary 4.6. Let $(\mathrm{X}, \mathrm{G})$ be a symmetric $\mathrm{G}$-metric space and $\mathrm{S}, \mathrm{T}: \mathrm{X} \rightarrow \mathrm{X}$. Suppose that

(i) $\mathrm{S}(\mathrm{X}) \subseteq \mathrm{T}(\mathrm{X})$;

(ii) $\mathrm{T}(\mathrm{X})$ is closed;

(iii) $\mathrm{S}$ is T-non-decreasing;

(iv) there exists $x_{0} \in X$ with $\mathrm{gx}_{0} \leqslant \mathrm{fx}_{0}$;

(v) if $\mathrm{T} x_{\mathrm{n}} \subset \mathrm{X}$ is a nondecreasing sequence (w.r.t. $\leqslant$ ) with $\mathrm{T} \mathrm{x}_{\mathrm{n}} \rightarrow \mathrm{T} z$ in $\mathrm{T}(\mathrm{X})$, then $\mathrm{Tu} \leqslant \mathrm{T}(\mathrm{Tu})$ and $\mathrm{T} \mathrm{x}_{\mathrm{n}} \leqslant \mathrm{Tu}$, for all $\mathrm{n} \in \mathrm{N}$;

(vi) there exists a right monotone simulation function $\zeta$ such that for every $(x, y) \in X \times X$ with $T x \leqslant T y$, we have

$$
\zeta(G(S x, S y, S z), H(S, T, x, y, z)) \geqslant 0
$$

where

$$
H(S, T, x, y, z)=\max \{G(T x, T y, T z), G(T x, S y, T z), G(T y, S x, T z)\}
$$

Then, $\mathrm{S}$ and $\mathrm{T}$ have a coincidence point. Further, if $\mathrm{S}$ and $\mathrm{T}$ commute at their coincidence points, then $\mathrm{S}$ and $\mathrm{T}$ have a common fixed point.

Proof. It can be proved independently by taking right monotone simulation function

$$
\zeta:[0, \infty) \times[0, \infty) \rightarrow \mathbb{R},
$$

as $\zeta(a, b)=b-\frac{a+2}{a+1} a$, for each $a, b \geqslant 0$.

\section{Acknowledgment}

The authors are thankful to both the referees for their valuable comments and suggestions.

\section{References}

[1] R. P. Agarwal, Z. Kadelburg, S. Radenović, On coupled fixed point results in asymmetric g-metric spaces, J. Inequal. Appl., 2013 (2013), 12 pages. 1

[2] R. P. Agarwal, E. Karapınar, A. F. Roldán-López-de Hierro, Fixed Point Theory in Metric Type Spaces, Springer, Cham, (2015).

[3] R. P. Agarwal, E. Karapınar, A. F. Roldán-López-de Hierro, Last remarks on G-metric spaces and related fixed point theorems, Rev. R. Acad. Cienc. Exactas Fis. Nat. Ser. A Mat. RACSAM, 110 (2016), 433-456. 1

[4] W. M. Alfaqih, R. Gubran, M. Imdad, Coincidence and Common Fixed Point Results under Generalized $(A, S)_{f^{-}}$ Contractions, Filomat, 32 (2018), 2651-2666.

[5] H. H. Alsulami, E. Karapınar, F. Khojasteh, A. F. Roldán-López-de Hierro, A proposal to the study of contractions in quasi-metric spaces, Discrete Dyn. Nat. Soc., 2014 (2014), 10 pages. 2.4

[6] H. Argoubi, B. Samet, C. Vetro, Nonlinear contractions involving simulation functions in a metric space with a partial order, J. Nonlinear Sci. Appl., 8 (2015), 1082-1094. 1, 1, 4.1

[7] S. Banach, Sur les opérations dans les ensembles abstraits et leur application aux équations intégrales, Fund. Math., 3 (1922), 133-181. 1

[8] D. W. Boyd, J. S. W. Wong, On nonlinear contractions, Proc. Amer. Math. Soc., 20 (1969), 458-464. 1

[9] M. Imdad, W. M. Alfaqih, I. A. Khan, Weak $\theta$-contractions and some fixed point results with applications to fractal theory, Adv. Difference Equ., 2018 (2018), 18 pages. 
[10] M. Jleli, B. Samet, A new generalization of the banach contraction principle, J. Inequal. Appl., 2014, (2014), 8 pages. 1

[11] E. Karapınar, Fixed points results via simulation functions, Filomat, 30 (2016), 2343-2350. 2.4

[12] E. Karapınar, A. F. Roldán-López-de Hierro, B. Samet, Matkowski theorems in the context of quasi-metric spaces and consequences on G-metric spaces, An. Ştiin. Univ. "Ovidius" Constana Ser. Mat., 24 (2016), 309-333. 1

[13] F. Khojasteh, V. Rakočević, Some new common fixed point results for generalized contractive multi-valued non-selfmappings, Appl. Math. Lett., 25 (2012), 287-293.

[14] F. Khojasteh, S. Shukla, S. Radenović, A new approach to the study of fixed point theory for simulation functions, Filomat, 29 (2015), 1189-1194. 1, 2, 2, 2, 2.4

[15] J. Matkowski, Integrable solutions of functional equations, Dissertationes Math. (Rozprawy Mat.), 127 (1975), 68 pages. 1

[16] N. Mizoguchi, W. Takahashi, Fixed point theorems for multivalued mappings on complete metric spaces, J. Math. Anal. Appl., 141 (1989), 177-188.

[17] Z. Mustafa, A New Structure for Generalized Metric Spaces: With Applications to Fixed Point Theory, Ph.D. thesis (University of Newcastle), Newcastle, (2005). 1, 1

[18] Z. Mustafa, B. Sims, A new approach to generalized metric spaces, J. Nonlinear Convex Anal., 7 (2006), 289-297. 1, 1

[19] O. Popescu, Some new fixed point theorems for $\alpha$-geraghty contraction type maps in metric spaces, Fixed Point Theory Appl., 2014 (2014), 12 pages.

[20] B. E. Rhoades, Some theorems on weakly contractive maps, Proceedings of the Third World Congress of Nonlinear Analysts, Part 4 (Catania, 2000). Nonlinear Anal., 47 (2001), 2683-2693.

[21] A. F. Roldán-López-de Hierro, E. Karapınar, C. Roldán-López-de Hierro, J. Martínez-Moreno, Coincidence point theorems on metric spaces via simulation functions, J. Comput. Appl. Math., 275 (2015), 345-355. 1, $2,2.4$

[22] D. Wardowski, N. Van Dung, Fixed points of F-weak contractions on complete metric spaces, Demonstr. Math., 47 (2014), 146-155. 1 